\title{
Diagnostic and prognostic value of a 7-panel mutation testing in thyroid nodules with indeterminate cytology: the SWEETMAC study
}

\author{
Stéphane Bardet $\mathbb{D}^{1}$ - Nicolas Goardon ${ }^{2}$ - Justine Lequesne ${ }^{3}$ - Dominique Vaur ${ }^{2}$ - Renaud Ciappuccini ${ }^{1}$. \\ Alexandra Leconte ${ }^{3} \cdot$ Hervé Monpeyssen $^{4} \cdot$ Virginie Saguet-Rysanek $^{5} \cdot$ Bénédicte Clarisse $^{3} \cdot$ Audrey Lasne-Cardon $^{6}$. \\ Fabrice Ménégaux ${ }^{7}$. Laurence Leenhardt ${ }^{8} \cdot$ Camille Buffet $^{8}$
}

Received: 6 May 2020 / Accepted: 27 June 2020 / Published online: 7 July 2020

(c) The Author(s) 2020

\begin{abstract}
Purpose The aim of this prospective study (ClinicalTrials.gov: NCT01880203) was to evaluate the diagnostic and prognostic value of a 7-panel mutation testing in the aspirates of thyroid nodules with indeterminate cytology (IC).

Methods Eligible patients had a thyroid nodule $\geq 15 \mathrm{~mm}$ with IC (Bethesda III-V) for which surgery had been recommended. Detection of BRAF and RAS mutations was performed using pyrosequencing and RET/PTC and PAX8/PPAR rearrangements using Real-Time quantitative reverse transcription-polymerase chain reaction (RT-PCR).

Results Among 131 nodules with IC, 21 (16\%) were malignant including 20 differentiated cancers and one thyroid lymphoma. Molecular abnormalities were identified in 15 nodules with IC corresponding to 10 malignant and 5 benign tumours. BRAF mutation was detected in 4 nodules all corresponding to classic PTC, and PAX8/PPAR rearrangement in 2 HCC. In contrast, RAS mutation was identified in eight nodules, of which four were malignant, and one RET/PTC3 rearrangement in a follicular adenoma. This data resulted in an accuracy of $88 \%$, sensitivity of $48 \%$, specificity of $95 \%$, positive-predictive value of $67 \%$, and negative-predictive value of $91 \%$. After a 56 month's follow-up, the proportion of excellent response was similar in patients with molecular alterations $(67 \%)$ and those without $(60 \%)$.

Conclusions By increasing the overall risk of cancer from 16 to $67 \%$ in mutated nodules and by diminishing it to $9 \%$ in wildtype, this study confirms the relevance of the 7-panel mutation testing in the diagnostic of nodules with IC. Genetic testing, however, did not predict outcome in the cancer patient subgroup.
\end{abstract}

Keywords Thyroid nodules $\cdot$ Diagnosis $\cdot$ Prognosis $\cdot$ Mutation $\cdot$ Thyroid cancer

Stéphane Bardet

s.bardet@baclesse.fr

1 Department of Nuclear Medicine and Thyroid Unit, Centre François Baclesse, Caen, France

2 Department of Molecular Biology, Centre François Baclesse, Caen, France

3 Department of Clinical Research, Centre François Baclesse, Caen, France

4 Thyroid Unit, American Hospital, Neuilly sur Seine, France

5 Department of Pathology, Centre François Baclesse, Caen, France

6 Department of Head and Neck Surgery, Centre François Baclesse, Caen, France

7 Department of Endocrine Surgery, Pitié Salpêtrière Hospital, IUC, University Paris VI, Paris, France

8 Thyroid and Endocrine Tumors Unit, Institute of Endocrinology, Pitié Salpêtrière Hospital, IUC Sorbonne University, Paris, France

\section{Introduction}

At least one woman out of two after 50 years old has a thyroid nodule. Owing to their frequency and the wide use of neck ultrasound (US), the clinical management of thyroid nodules has become a public health issue. Facing a thyroid nodule, the clinician has to recognize functional autonomy and to evaluate the risk of cancer. Although thyroid nodules are common, only a small fraction $(\sim 5 \%)$ corresponds to malignant tumours which are generally of good prognosis. Assessing the risk of cancer is mainly based on thyroid cytology after fine needle aspiration biopsy (FNAB) using the Bethesda classification [1]. This is a good, if not a perfect method for identifying patients with thyroid cancer. The main limitation is represented by indeterminate cytology (IC) which occurs in up to $25 \%$ of cases and does not allow differentiating between benign and malignant nodules. Indeterminate cytology comprises Bethesda class 
III (atypia of undetermined significance/follicular lesion of undetermined significance (AUS/FLUS)), class IV (follicular neoplasm/suspicious for follicular neoplasm (FN) or Hürthle cell neoplasm (FN/SFN)) and at a lesser degree, class V (suspicious for malignancy (SM)). Surgery is strongly recommended in Bethesda $\mathrm{V}$ associated with a high risk of cancer up to $75 \%$. In clinical practice, surgery still remains a usual option for Bethesda III or IV nodules although the risk of cancer does not exceed 20-25\%. As a result, $\sim 80 \%$ of operations can be $a$ posteriori considered as useless in those categories. Given the potential morbidity of thyroid surgery for parathyroid glands and recurrent nerve, and the necessity of hormonal treatment after total thyroidectomy, a more accurate preoperative assessment is needed to better select patients for surgery. This trend towards a risk-adapted approach, personalized therapy and treatment de-escalation was strengthened in the 2015 ATA guidelines [2]. Improving the characterization of nodules would allow surveillance in patients with likely benign nodules and enable a shift to the most appropriate surgical procedure in those with malignant nodules also taking into account the assumed prognosis of cancer. From this point of view, although the presence of somatic mutations, particularly $B R A F$ mutation [3], has been shown to be associated with more aggressive disease, the prognostic impact of molecular testing in the aspirates of IC nodules on the longterm outcome of patients with thyroid cancer has not been evaluated so far.

In the last decade, tools of molecular analysis or imaging have been developed to improve the diagnosis of thyroid nodules. Investigating the presence of somatic mutations, genomic rearrangements or gene fusions in thyroid FNA specimens has been shown relevant in nodules with IC [4]. Testing for single mutations such as $B R A F$ V600E has a high specificity for cancer but low sensitivity [5]. Testing for a limited panel of mutations (such as BRAF, RAS, RET/PTC, PAX8/PPAR ) enables to increase sensitivity while maintaining a good specificity [6]. More recently, ThyroSeq v2.1 next-generation sequencing (NGS) multi-gene panel of molecular markers has been shown to provide high sensitivity, $90.9 \%$ and specificity, $92.1 \%$ in Bethesda III nodules [7]. Sophistication of ThyroSeq v3 improves sensitivity at $94.1 \%$ while moderately lowers specificity at $81.6 \%$ and enables to avoid $82 \%$ of unnecessary surgeries in patients with histologically proven benign nodules [8]. Also, recent studies in patients with IC nodules using genomic sequencing classifier have reported sensitivity ranging from 91 to $100 \%$ and specificity from 68 to $93 \%$ [9, 10].

Besides molecular testing, efforts have been made to look for imaging methods in capacity to refine diagnosis of nodules with IC. Recently, we reported the results of a prospective bicentric study designed to assess the relevance of US and shear wave elastography. Both methods failed to discriminate benign and malignant nodules [11]. The other objective of this study was to evaluate in the same patients the diagnostic and prognostic values of a 7-panel mutation testing on the indeterminate cytological specimens. We present here the results of that study.

\section{Patients and methods}

\section{Patients}

The study protocol was approved by the Local Ethics Committee (Ref. 2012-35, Comité de protection des personnes Nord-Ouest III) and the French Health Authorities (Ref 130213B-22). This trial is registered as ID-RCB 2012A01313-40, ClinicalTrials.gov NCT01880203. It was conducted according to the provisions of the Declaration of Helsinki and the Good Clinical Practice Guidelines of the International Conference of Harmonization. Written informed consent was obtained from all patients.

As previously described [11], eligible patients had a thyroid nodule $\geq 15 \mathrm{~mm}$ with $\mathrm{IC}$ according to Bethesda classification in the six months before inclusion, for whom surgery had been recommended. Indeterminate cytology included class III, IV and V sub-categories and was confirmed by an experienced cytologist working in the other participating centre.

\section{Fine needle aspiration (FNA)}

The FNA procedures were conducted under US guidance into the nodule of interest. The study protocol provided for two dedicated passes of FNA washed in a tube containing nucleic acid preservative solution (RNA protect ${ }^{\oplus}$, QIAGENTM) which was frozen at $-20^{\circ} \mathrm{C}$ until analysis.

\section{Nucleic acids extraction}

Total RNA and DNA were extracted from FNA samples using AllPrep DNA/RNA Micro Kit (QIAGENTM) according to the manufacturer's protocol. The amount of total RNA and DNA was determined by spectrophotometry using NanoVue (GE Health Care Bio-Science, Piscataway, NJ, USA) and used as template for RT-PCR and PCR amplification.

\section{Detection of point mutations}

DNA was amplified by polymerase chain reaction (PCR) using the following primers (BRAF: forward: 5'-biotin- CTT CATAATGCTTGCTCTGATAGG-3', reverse: 5'-GGCCA AAAATTTAATCAGTGGAA-3'; HRAS: forward: 5'-ATT 
GATGGGGAGACGTGCCTGTTG-3', reverse: 5'-biotinTACTGGTCCCGCATGGCGCTGT-3'; KRAS: forward: 5'- CATGTTCTAATATAGTCACATTTTCAT-3', reverse: 5'- biotin- AGCTGTATCGTCAAGGCACTCTT-3'; NRAS: forward: 5'- GCAAATACACAGAGGAAGCCTTCG-3', reverse: 5'-biotin-GGCCAAAAATTTAATCAGTGGAA$3^{\prime}$;) with a product size of $226 \mathrm{bp}, 77 \mathrm{bp}, 121 \mathrm{pb}$ and $137 \mathrm{bp}$ respectively. DNA was amplified using the Quantitec Multiplex PCR NoROX kit (QIAGEN ${ }^{\mathrm{TM}}$ ) according to the manufacturer's protocol. The cycling conditions were: 1for $B R A F$ and $K R A S: 95^{\circ} \mathrm{C}$ for $15 \mathrm{~min}, 45$ cycles of $95^{\circ} \mathrm{C}$ for $20 \mathrm{~s}, 60^{\circ} \mathrm{C}$ for $30 \mathrm{~s}$ and $72{ }^{\circ} \mathrm{C}$ for $30 \mathrm{~s}$, final extension at $72{ }^{\circ} \mathrm{C}$ for $20 \mathrm{~min}$; 2- for $N R A S: 95^{\circ} \mathrm{C}$ for $10 \mathrm{~min}, 30$ cycles of $94^{\circ} \mathrm{C}$ for $20 \mathrm{~s}, 70^{\circ} \mathrm{C}$ for $20 \mathrm{~s}$ with a decrease of $0.5^{\circ} \mathrm{C}$ per cycle and $72{ }^{\circ} \mathrm{C}$ for $45 \mathrm{~s}, 19$ cycles of $94^{\circ} \mathrm{C}$ for $20 \mathrm{~s}, 50^{\circ} \mathrm{C}$ for $20 \mathrm{~s}$ and $72^{\circ} \mathrm{C}$ for $45 \mathrm{~s}$, final extension at $72{ }^{\circ} \mathrm{C}$ for $10 \mathrm{~min}$; 3- for $H R A S: 95^{\circ} \mathrm{C}$ for $10 \mathrm{~min}, 40$ cycles of $95^{\circ} \mathrm{C}$ for $30 \mathrm{~s}, 69^{\circ} \mathrm{C}$ for $45 \mathrm{~s}$ and $72{ }^{\circ} \mathrm{C}$ for $30 \mathrm{~s}$, final extension at $72{ }^{\circ} \mathrm{C}$ for $10 \mathrm{~min}$.

Mutation detection of BRAF codons 600 and 601 (sequencing primer: 5'-CCACTCCATCGAGATT-3'), HRAS codon 61 (sequencing primer: 5'-TCCTGGATA CCGCCG-3'), KRAS codons 12 and 13 (sequencing primer: 5'-CTTGTGGTAGTTGGAGCT-3'), NRAS codon 61 (sequencing primer: 5'-GACATACTGGATACAGCT-3') using the Pyrosequencing PyroMark ${ }^{\mathrm{TM}}$ Q24 system was done following the manufacturer's instructions.

\section{Detection of rearrangements}

Real-time quantitative reverse transcription-polymerase chain reaction (RT-PCR) mixture was prepared using $40 \mathrm{nM}$ of each primer set and probes as previously described [12], 2X Quantitec Probe RT-PCR master Mix (QIAGEN ${ }^{\mathrm{TM}}$ ), Quantitec RT Mix (QIAGENTM) and $10 \mathrm{ng}$ of RNA in a final reaction volume of $25 \mu \mathrm{L}$ according to the manufacturer's protocol. Reverse transcription twostep PCR thermal cycling for cDNA amplification and real-time data acquisition were performed with a 7500 FAST (Thermofisher ${ }^{\mathrm{TM}}$ ) Real-Time PCR System using the following cycle conditions: a reverse transcription step of $50{ }^{\circ} \mathrm{C}$ for $30 \mathrm{~min}$, a cDNA denaturation step of $95^{\circ} \mathrm{C}$ for $15 \mathrm{~min}$ followed by 50 cycles amplification of $94{ }^{\circ} \mathrm{C}$ for $15 \mathrm{~s}$ and $60^{\circ} \mathrm{C}$ for $1 \mathrm{~min}$. Negative control (no cDNA) and positive controls (RNA from tumours or cell lines known to carry a particular rearrangement was used as a positive control.) were cycled in parallel with each run. To decrease the likelihood of false negatives, GAPDH was amplified in parallel for each sample. Fluorescence data were analysed by the 7500 Fast Dx software and expressed as $\mathrm{Ct}$, the number of cycles needed to generate a fluorescent signal above a predefined threshold. Baseline and threshold values were set by the 7500 Fast Dx software. Samples with a delta Ct inferior to 10 have been considered as positive.

\section{Surgery and histological examination}

Thyroid surgery was performed in each participating institution and consisted in either lobectomy or total thyroidectomy. The surgeon oriented the resected specimen and localized the nodule for pathological diagnosis with the support of the descriptive diagram. The 2004 World Health Organization criteria were used for diagnosis [12].

\section{Initial treatment and follow-up for patients with differentiated thyroid cancer}

The initial treatment for patients with differentiated thyroid cancer (DTC) was a combination of thyroid surgery, with or without neck dissection, and treatment with radioactive iodine (RAI). This treatment was discussed in a multidisciplinary team and was not affected by the presence or absence of molecular markers in FNAB samples.

After initial treatment, patients were assessed at 9-12 months and then annually. The response to treatment was evaluated according to the ATA 2015 guidelines [2]. Excellent response was defined by negative imaging and either suppressed thyroglobulin $(\mathrm{Tg})<0.2 \mathrm{ng} / \mathrm{mL}$ or $\mathrm{TSH}-$ stimulated $\mathrm{Tg}<1 \mathrm{ng} / \mathrm{mL}$, biochemical incomplete response by negative imaging and suppressed $\mathrm{Tg} \geq 1 \mathrm{ng} / \mathrm{mL}$ or stimulated $\mathrm{Tg} \geq 10 \mathrm{ng} / \mathrm{mL}$ or rising anti-Tg antibodies ( $\mathrm{TgAb}$ ) levels, structural incomplete response by structural or functional evidence of disease with any $\mathrm{Tg}$ level, with or without $\mathrm{TgAb}$, and indeterminate response by nonspecific findings on imaging studies, with non-stimulated $\mathrm{Tg}$ between 0.2 and $1 \mathrm{ng} / \mathrm{mL}$ or stimulated $\mathrm{Tg}$ between 1 and $10 \mathrm{ng} / \mathrm{mL}$, or $\mathrm{TgAb}$ stable or declining in the absence of structural or functional disease.

\section{Statistical analysis}

Patient characteristics and patient subgroups were compared using the Wilcoxon or Kruskal-Wallis test (continuous variables) and chi-square or Fisher's exact test (nominal variables), as appropriate. All tests were two-sided, and a $p$ value $<0.05$ was considered statistically significant. Analyses were performed with R (version 3.4.0). Sensitivity, specificity, positive predictive value (PPV), negative predictive value (NPV) and accuracy were computed to assess the diagnostic performances of the 7-panel testing. As an exploratory analysis, the link between diagnostic performances and cancer prevalence, PTC rate and $B R A F$ mutated PTC rate in previous studies and ours was assessed through a linear model. 


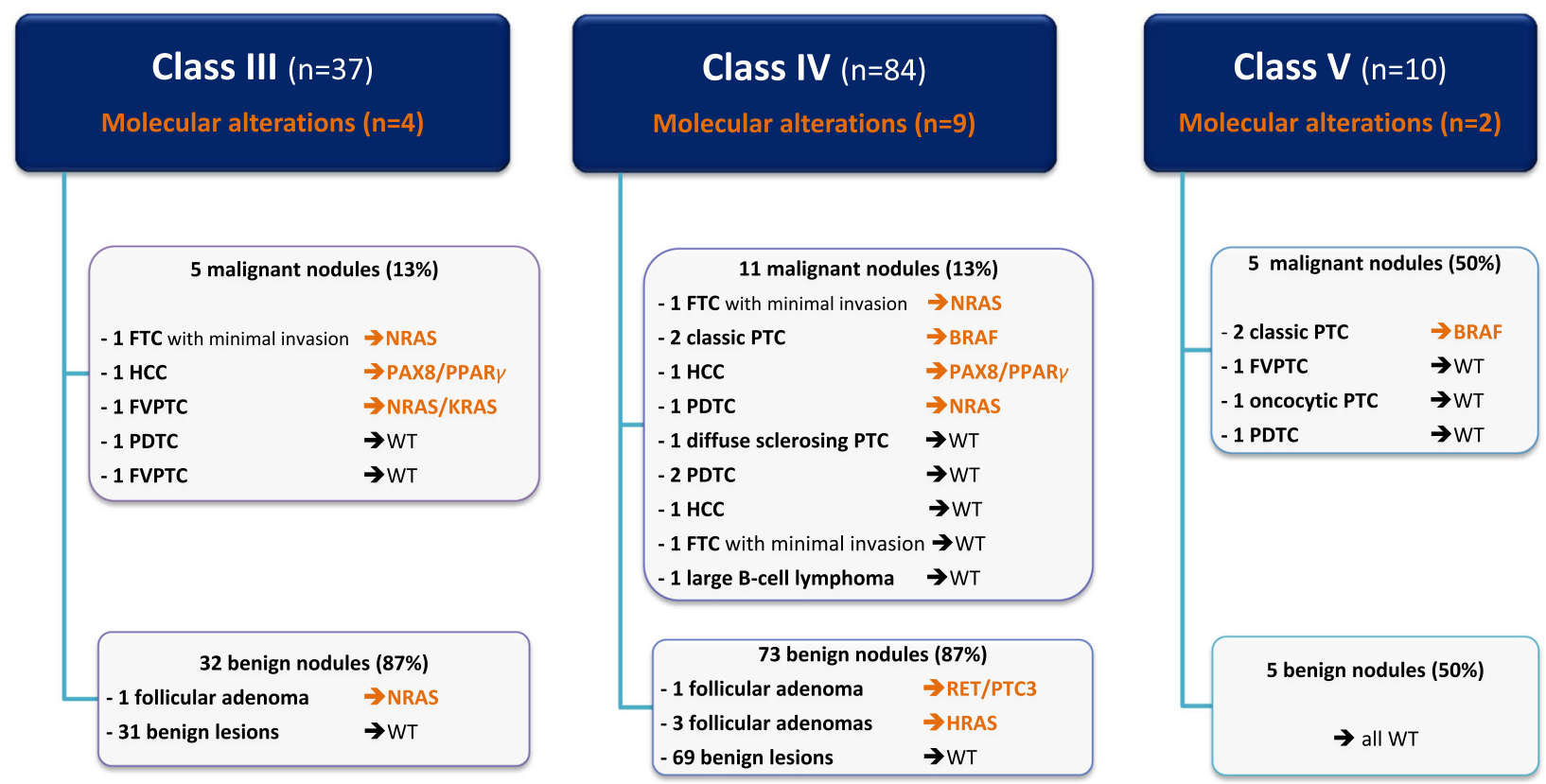

Fig. 1 Molecular alterations in patients with malignant or benign nodules for each cytological subgroup (Bethesda III, IV and V). WT wild-type, PTC papillary thyroid cancer, FVPTC papillary thyroid cancer with follicular variant, FTC follicular thyroid carcinoma, HCC Hürthle-cell carcinoma, PDTC poorly differentiated thyroid carcinoma

\section{Results}

\section{Patient characteristics}

As previously described [11], 140 patients were initially enroled in this study. Since nine patients were secondarily excluded (consent withdrawal, $n=4$; spontaneous nodule shrinkage, $n=1$, surgery cancelled for comorbidities, $n=1$; surgery performed outside the participating centres, $n=3$ ), 131 patients were assessable.

\section{Cytological and pathological data}

From a cytological point of view, 37 patients $(28 \%)$ had a nodule scored class III, 84 (64\%) class IV and 10 (8\%) class V (Fig. 1). Central review confirmed the IC status in all 131 nodules.

Among 131 nodules, $21(16 \%)$ were pathologically confirmed as malignant and 110 were benign. Malignant nodules included 9 PTC (classic variant, $n=4$; follicular variant [FVPTC], $n=3$; oncocytic variant, $n=1$; diffuse sclerosing variant, $n=1$ ), 3 follicular thyroid carcinomas (FTC) with minimal invasion, 3 Hürthle-cell carcinoma (HCC), 5 poorly differentiated carcinomas (PDTC) and one large B-cell lymphoma. In the classes III, IV and V, the rates of cancer were $13 \%, 13 \%$ and $50 \%$, respectively. Benign nodules included 61 follicular adenomas, 26 nodular hyperplasia, 15 oncocytic adenomas, 6 other pathological diagnoses (1 multinodular goiter, 1 Grave's disease, 1 trabecular hyalinized adenoma, 3 lymphocytic thyroiditis) and 2 tumours of uncertain malignant potential. The median size of the 131 nodules was $30 \mathrm{~mm}$ (range, 15-71). According to EU-TIRADS classification [13], there were 52 (40\%) nodules scored Tirads 3, 33 (25\%) Tirads 4 and 46 (35\%) Tirads 5 with no significant differences between malignant and benign nodules as previously reported [11].

\section{Molecular analysis on cytological specimens}

Figure 1 shows the molecular alterations in patients with malignant or benign nodules for each cytological subgroup. Molecular abnormalities were identified in $15 / 131$ nodules including $4 B R A F$ mutations, 8 RAS mutations (4 NRAS, 3 HRAS, 1 with both KRAS and NRAS mutations), 1 RET/ $P T C 3$ rearrangement and $2 P A X 8 / P P A R \gamma$ rearrangements. Ten $(47.6 \%)$ of the 21 malignant nodules presented molecular abnormalities vs $5(4.5 \%)$ of the 110 benign nodules $(p<0.001) . B R A F$ mutation was identified in 4 nodules all corresponding to classic PTC. PAX8/PPAR $\gamma$ rearrangements were also associated with an HCC in the two patients where they were found. In contrast, RAS mutation was detected in 8 nodules, among which 4 were malignant (2 FTC, 1 FVPTC and 1 PDTC). Last, one RET/PTC3 rearrangement was detected in a follicular adenoma.

Overall, molecular analysis had an accuracy of $88 \%$, a sensitivity of $48 \%$, a specificity of $95 \%$, a PPV of $67 \%$ and a NPV of $91 \%$ (Table 1). Therefore, while the probability of cancer before testing in nodules with IC was $16 \%$, the 
Table 1 Test performances in the whole cohort of patients, and in the Besthesda III, IV and $\mathrm{V}$ groups

\begin{tabular}{|c|c|c|c|c|c|c|c|c|}
\hline & \multicolumn{2}{|l|}{ All } & \multicolumn{2}{|c|}{ Bethesda III } & \multicolumn{2}{|c|}{ Bethesda IV } & \multicolumn{2}{|c|}{ Bethesda V } \\
\hline & \multicolumn{2}{|l|}{$n=131$} & \multicolumn{2}{|l|}{$n=37$} & \multicolumn{2}{|l|}{$n=84$} & \multicolumn{2}{|l|}{$n=10$} \\
\hline & Estimate & $95 \% \mathrm{CI}$ & Estimate & $95 \% \mathrm{CI}$ & Estimate & $95 \% \mathrm{CI}$ & Estimate & $95 \% \mathrm{CI}$ \\
\hline True prevalence & 16 & [10-23] & 14 & [5-29] & 13 & {$[7-22]$} & 50 & [19-81] \\
\hline Sensitivity & 48 & [26-70] & 60 & [15-95] & 45 & [17-77] & 40 & [5-85] \\
\hline Specificity & 95 & [90-99] & 97 & [84-100] & 95 & [87-98] & 100 & [48-100] \\
\hline $\begin{array}{l}\text { Positive predictive } \\
\text { value (PPV) }\end{array}$ & 67 & [38-88] & 75 & [19-99] & 56 & [21-86] & 100 & [16-100] \\
\hline $\begin{array}{l}\text { Negative predictive } \\
\text { value (NPV) }\end{array}$ & 91 & [84-95] & 94 & [80-99] & 92 & [83-97] & 62 & [24-91] \\
\hline Accuracy & 88 & [81-93] & 92 & [78-98] & 88 & [79-94] & 70 & [35-93] \\
\hline
\end{tabular}

probability after testing increased to $67 \%$ in mutatednodules and decreased to $9 \%$ in wild-type ones. There was no significant difference between the Bethesda III, IV and V subgroups in terms of accuracy, sensitivity, specificity, PPV or NPV.

\section{Outcome of patients with thyroid cancer}

The patient with thyroid lymphoma and a patient with an NRAS-mutated FTC who was long-lost after initial treatment were excluded from the prognostic analysis. Of the 19 remaining DTC patients, 9 had a mutated tumour and 10 a wild-type tumour (Table 2). At 9-12 months after initial therapy, a similar proportion of patients with mutated and wild-type cancers presented excellent response $(55 \%(5 / 9)$ vs $40 \%(4 / 10) ; p=0.66)$. Three of 19 DTC patients received additional treatments because of persistent or recurrent disease, two with mutated tumour and one with wild-type. At last visit, after a median follow-up of 56 months (16-81), the proportion of excellent response was similar in patients with molecular alterations and those without $(67 \%(6 / 9)$ vs $60 \%(6 / 10) ; p=1)$.

\section{Comparison of present data with previous studies}

The analysis of the present data with previously reported studies [6, 14-22] is shown in Table 3 and in Fig. 2. In each study, we extracted the nodules with AUS/FLUS, FN/SFN or SM cytology, or Bethesda classes III, IV and $\mathrm{V}$, or with "indeterminate" cytology. Only nodules operated on were taken into account for analysis. The number of cases in each study varied from 23 to 513 , cancer prevalence from 16 to $56 \%$, PTC rate from 1 to $56 \%$ and rate of $B R A F$ positive PTC tumours from 0 to $24 \%$. Sensitivity ranged from 18 to $81 \%$, specificity from 86 to $100 \%$, PPV from 19 to $100 \%$ and NPV from 64 to $91 \%$. The sensitivity (48\%) and PPV (67\%) estimated in our series were generally lower than in other studies while NPV (91\%) was slightly higher.
Although not significant, data shows a trend to a link between diagnostic performances of genetic testing and cancer prevalence, PTC rate and proportion of PTC harbouring $B R A F$ mutations in each cohort, especially regarding sensitivity and PPV (Fig. 2).

\section{Discussion}

This prospective bicentric study confirms the clinical relevance of a 7-panel mutational testing in the characterization of cytologically indeterminate nodules. Molecular testing shows a good specifity (95\%), a more limited sensitivity $(48 \%)$ and an acceptable accuracy $(88 \%)$. In this series of patients with a $16 \%$ pre-test probability of cancer, a $67 \%$ PPV and 91\% NPV mean that the post-test probability increased to $67 \%$ in mutated-nodules and decreased to $9 \%$ in wild-type ones.

The impact of a 7-panel mutational testing on the diagnosis of IC nodules has been reported in previous studies [6, 14-22]. As shown in Fig. 2, the analysis of the present data and the literature shows that our sensitivity (48\%) and PPV $(67 \%)$ was generally lower than in previous studies while NPV (91\%) was moderately higher. These studies were conducted between 2009 and 2018, and included nodules with variable proportions of AUS/FLUS, FN/SFN or SM cytology, using Bethesda classification or not, resulting in a wide range of cancer prevalence from 16 to $56 \%$. Similarly, the PTC rates were highly variable ranging from 1 to $56 \%$ as well as the proportions of $B R A F$ mutated PTC tumours from 0 to $24 \%$. Given its frequency, the presence of $B R A F$ mutations significantly affects the results of the 7-panel testing in IC nodules. BRAF mutation is characteristic of PTC but only a part of them (45 to $80 \%$ ) are $B R A F$ mutated. This variable proportion is linked to pathological variants [23], classic PTC tumours being more often $B R A F$ positive than other PTC variants, and to the geographical origin of patients with Koreans showing very high proportions of $B R A F$ mutated PTC tumours [24]. The 


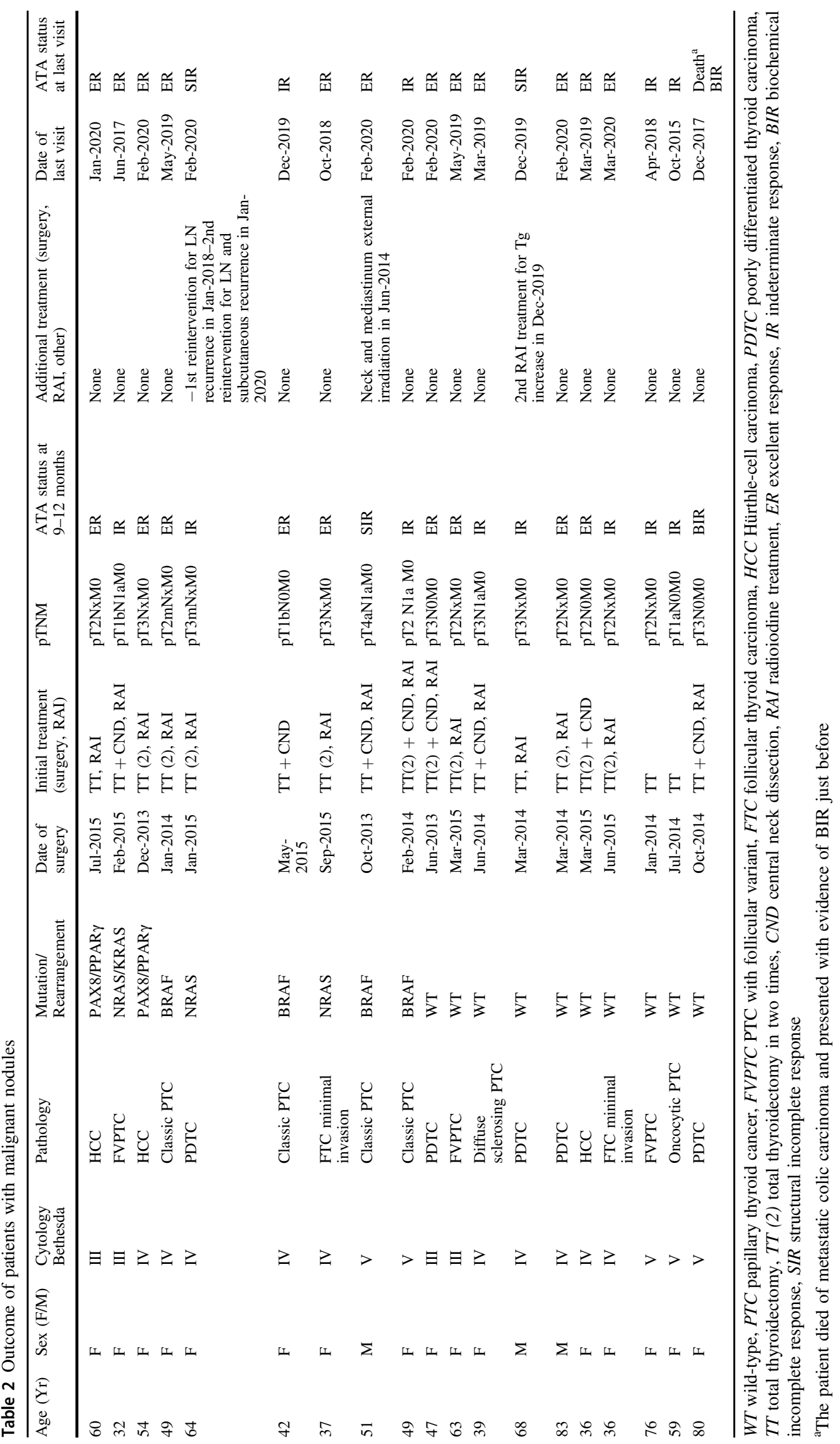


Table 3 Analysis of the present data in comparison with that of the literature

\begin{tabular}{|c|c|c|c|c|c|c|c|c|c|}
\hline \multirow{2}{*}{$\begin{array}{l}\text { Reference 1st author, } \\
\text { yr, [ref. number] }\end{array}$} & \multirow{2}{*}{$\begin{array}{l}\text { Cytology ( } n \text { in each } \\
\text { subcategory) }\end{array}$} & \multirow{2}{*}{$\begin{array}{l}\text { Operated } \\
\text { nodules, } n\end{array}$} & \multirow{2}{*}{$\begin{array}{l}\text { Malignant nodules, } \\
n(\%)\end{array}$} & \multirow[t]{2}{*}{ PTC, $n(\%)$} & \multirow{2}{*}{$\begin{array}{l}\text { BRAF positive } \\
\text { PTC, } n(\%)\end{array}$} & \multicolumn{4}{|c|}{ Test performance, $\%$} \\
\hline & & & & & & Se. & Sp. & PPV & NPV \\
\hline Nikiforov 2009 [19] & $\begin{array}{l}\text { FLUS (21), FN } \\
(23), \text { SM (7) }\end{array}$ & 51 & $20(39 \%)$ & $16(31 \%)$ & $7(14 \%)$ & 75 & 100 & 100 & 86 \\
\hline Cantara 2010 [18] & $\begin{array}{l}\text { Indeterminate (41), } \\
\text { SM (54) }\end{array}$ & 95 & $53(56 \%)$ & $53(56 \%)$ & $23(24 \%)$ & 81 & 98 & 98 & 80 \\
\hline Nikiforov 2011 [6] & $\begin{array}{l}\text { AUS/FLUS (247), FN/ } \\
\text { SFN (214), SM (52) }\end{array}$ & 513 & $121(24 \%)$ & $110(21 \%)$ & $17(3 \%)$ & 61 & 98 & 89 & 89 \\
\hline $\begin{array}{l}\text { Beaudenon- } \\
\text { Huibregtse } 2014 \text { [17] }\end{array}$ & $\begin{array}{l}\text { AUS/FLUS (22), FN/ } \\
\text { SFN (19), SM (12) }\end{array}$ & 53 & $25(47 \%)$ & na & na & 44 & 89 & 79 & 64 \\
\hline Eszlinger 2014 [16] & Indeterminate & 141 & $22(16 \%)$ & $2(1 \%)$ & $0(0 \%)$ & 18 & 86 & 19 & 85 \\
\hline Eszlinger 2015 [15] & Thy 3 (163), Thy 4 (39) & 202 & $83(41 \%)$ & $57(28 \%)$ & $37(18 \%)$ & 60 & 92 & 92 & 77 \\
\hline Labourier 2015 [14] & III (58) IV (51) & 109 & $35(32 \%)$ & na & na & 69 & 86 & 71 & 85 \\
\hline Bongiovanni 2015 [20] & FN/SFN (23) & 23 & $4(17 \%)$ & $1(4 \%)$ & $0(0 \%)$ & 75 & 95 & 95 & 75 \\
\hline Mancini 2012 [21] & Thy 3 (38), Thy 4 (9) & 47 & $17(36 \%)$ & na & na & 59 & 90 & 77 & 79 \\
\hline Bellevicine 2020 [22] & $\begin{array}{l}\text { AUS/FLUS (86), FN/ } \\
\text { SFN (34), SM (57) }\end{array}$ & 177 & $93(53 \%)$ & $82(46 \%)$ & $39(48 \%)$ & 63 & 67 & 68 & 62 \\
\hline Present study & III (37), IV (84), V (10) & 131 & $21(16 \%)$ & $9(7 \%)$ & $4(3 \%)$ & 48 & 95 & 67 & 91 \\
\hline
\end{tabular}

III, IV, V: for Bethesda class III, IV or V

Thy 3, equivalent to FN/SFN; Thy 4, equivalent to SM

AUS/FLUS atypia of undetermined significance/follicular lesion of undetermined significance, $F N / S F N$ follicular neoplasm/suspicious for follicular neoplasm (FN) or Hürthle cell neoplasm, SM suspicious for malignancy

quite low sensitivity observed in the present study (48\%) can be explained by a $16 \%$ cancer prevalence and a $7 \%$ PTC rate at the low end of the expected range. Nevertheless, the histological distribution of the study group is consistent with what we could expect from IC, namely a combination of classic PTC (19\%), FVPTC (14\%), FTC (14\%), and HCC (14\%) and PDTC (24\%). As cancer prevalence also impacts NPV and PPV [25], this could have resulted in "underestimating" a 67\% PPV and "overestimating" a $91 \%$ NPV.

The prevalence of $P A X 8 / P P A R \gamma$ rearrangements is generally limited in IC nodules with no cases reported in some studies $[15,18]$ and only one in others [17, 19]. Our data confirms that $P A X 8 / P P A R \gamma$ rearrangements are cancer specific. Nevertheless, whereas $P A X 8 / P P A R \gamma$ rearrangements were identified in three FVPTC and one FTC in Nikiforov's study [6], in our series there were associated with two patients with HCC. The findings in the three HCC of our cohort (i.e., two cases with $P A X 8 / P P A R \gamma$ rearrangements and one wild-type tumour) were quite unexpected. Indeed, the prevalence of $P A X 8 / P P A R \gamma$ rearrangements is generally low in HCC, estimated at $5 \%$ in the review by Maximo et al [26] although rates up to $27 \%$ have already been reported [27]. The association between RET/PTC rearrangements and HCC is more prevalent and has been estimated at $35 \%$ [26]. Comprehensive analysis of the molecular landscape of HCC has very recently been achieved showing that these tumours exhibit a wide range of recurrent mutations, notably of the mitochondrial genome and high DNA copynumber alterations [28, 29].

In contrast, and as expected, RET/PTC rearrangements and $R A S$ mutations presented more limited diagnostic values. No RET/PTC rearrangements were found in malignant tumours and one RET/PTC3 was detected in a benign nodule. The presence of RET/PTC rearrangements is possible in benign nodules and a recent systematic review in 2239 benign lesions from 38 studies showed a prevalence of RET/PTC rearrangements ranging from $0 \%$ to $68 \%$ [30]. A study performed in PTC tumours also suggests that the variability in the rate of RET/PTC rearrangement could also be related to the use of different detection methods and tumour genetic heterogeneity [31]. With respect to RAS mutations, they were detected in eight nodules, half of them corresponding to malignant lesions (2 FTC, 1 FVPTC, 1 PDTC) leading to a 50\% PPV. Although comprehensive pathological data was available in a few previous studies [6, 15, 16], true-positive $R A S$ mutations were observed mainly in FVPTC or FTC, and sometimes in classic PTC, HCC or PDTC. False positives were found in all previous studies, and the estimated PPV for RAS testing ranged from 13 to $92 \%[6,15,16]$. As in previous studies, mutations were present in follicular adenomas. No non-invasive follicular thyroid neoplasm with papillary-like nuclear features (NIFTP) was found in our series. Recently, it has been 

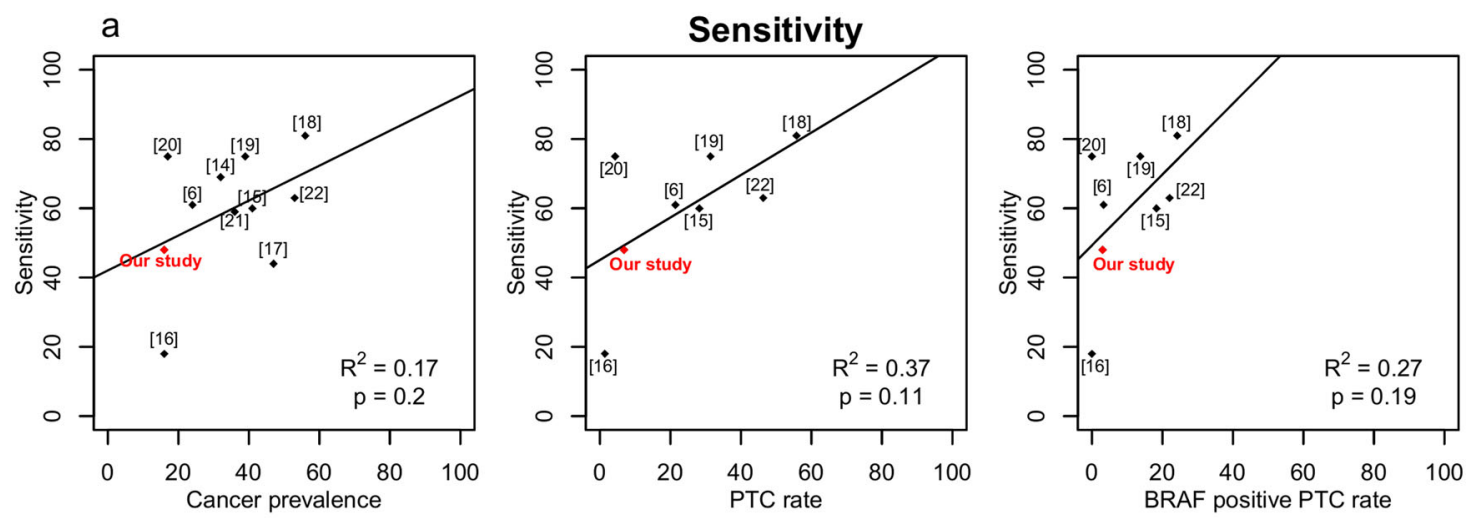

b

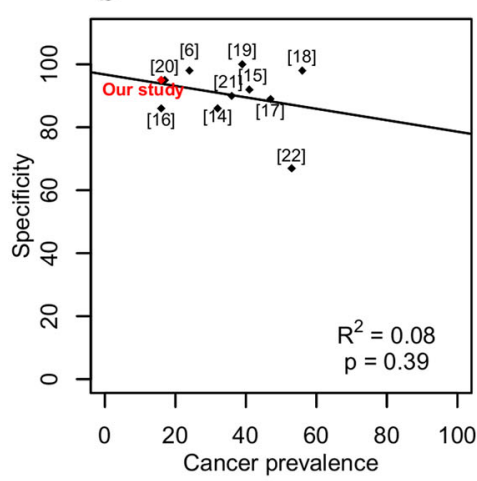

Specificity
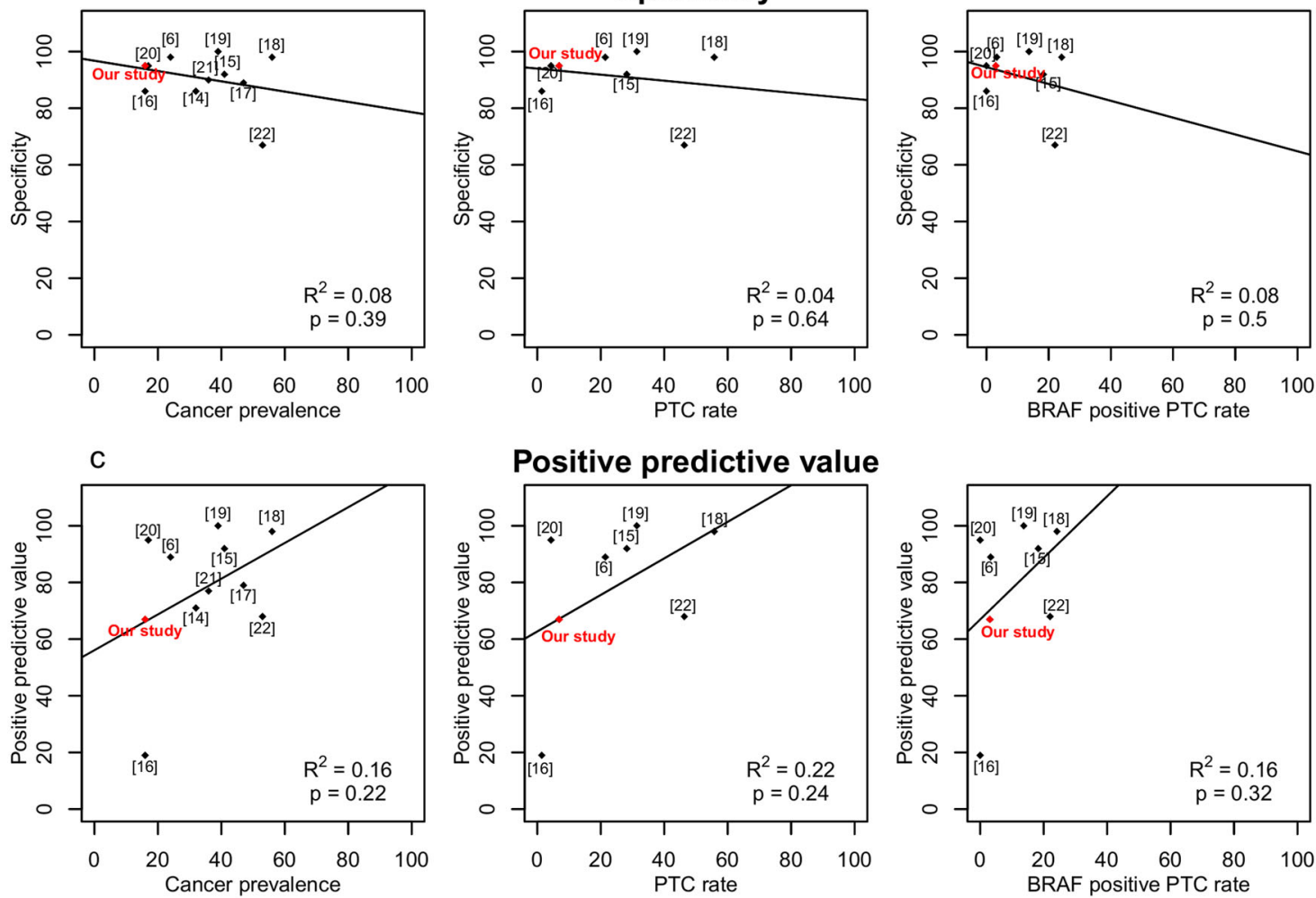

Positive predictive value
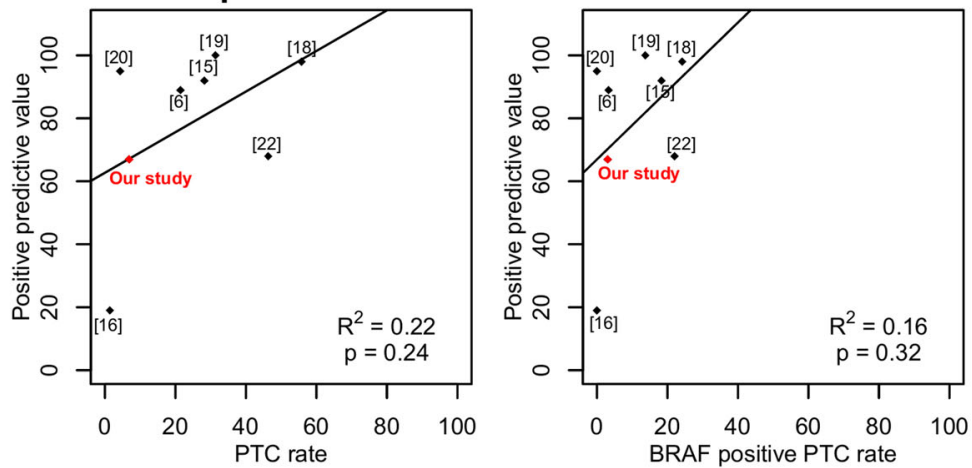

Negative predictive value
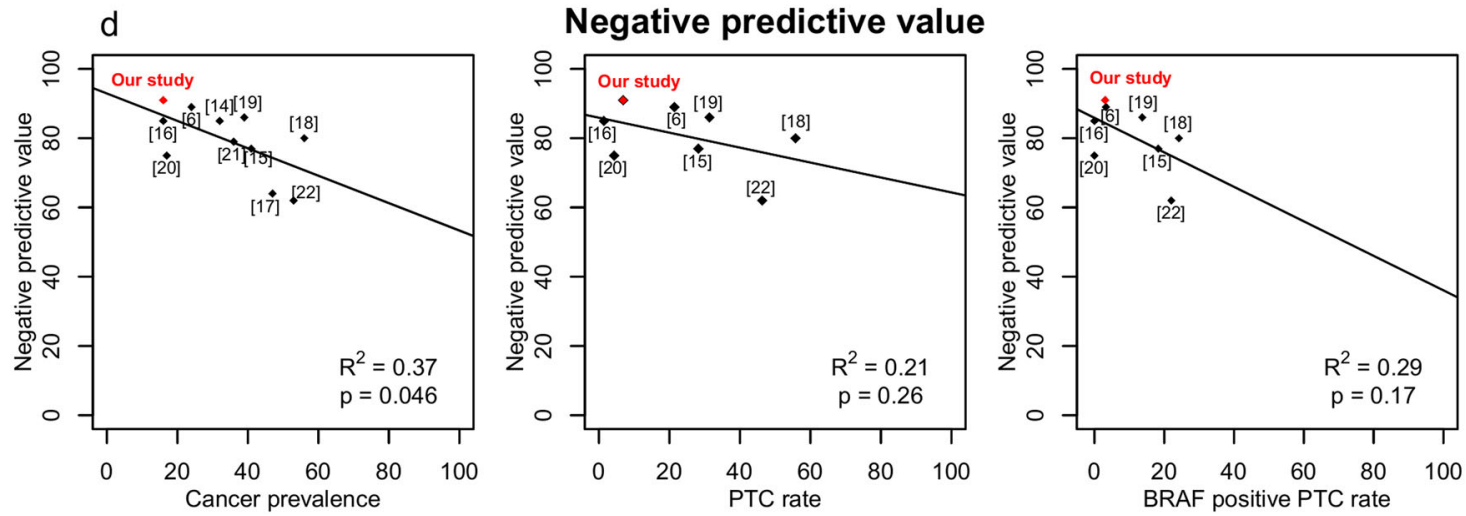

Fig. 2 Test performances (a, sensitivity; $\mathbf{b}$, specificity; c, PPV; d, NPV) according to cancer prevalence, PTC rate and $B R A F$ positive PTC rate in previous studies $(6,12,14-20)$ and in the present study. The quality of the linear model adjustment is displayed on each graph $\left(R^{2}\right.$ and $p$ value $)$ 
Fig. 3 Proposal for the use of 7panel testing to guide clinical decision in patients with cytologically indeterminate nodules

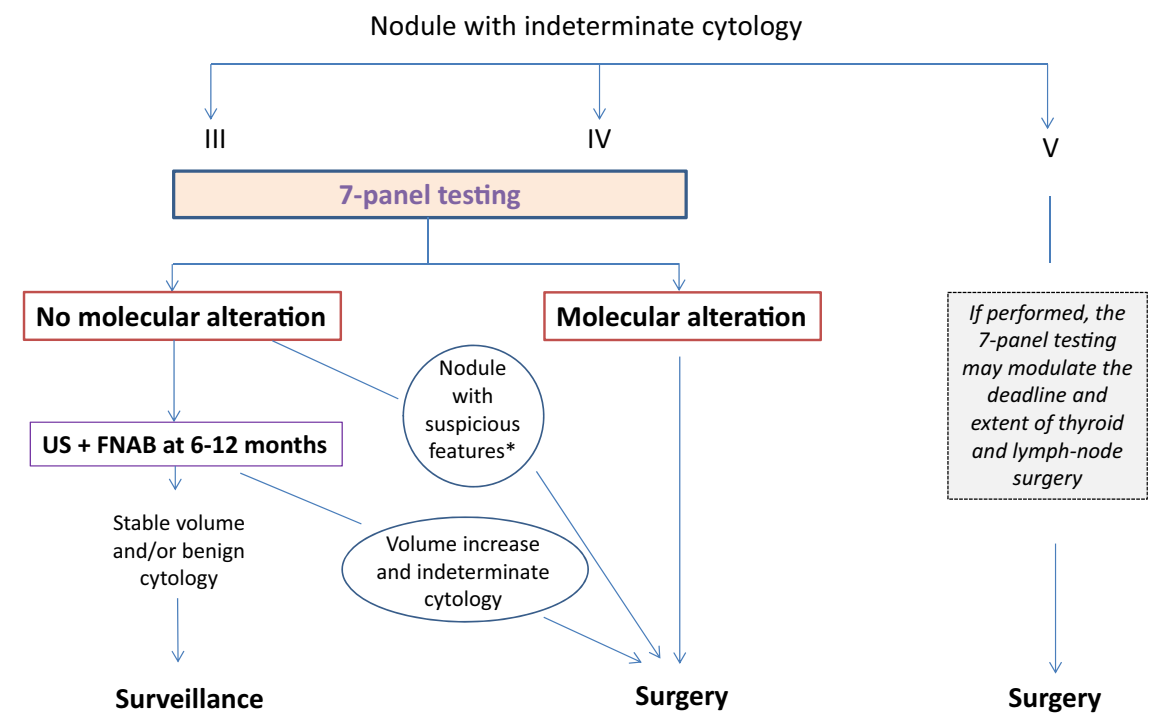

reported that a substantial proportion (47\%) of NIFTP could harbour NRAS mutations [32].

Based on our data and that of literature, a flow chart for the use of 7-panel testing to guide clinical decision in patients with IC nodules is proposed in Fig. 3. Given the generally high risk of cancer in Bethesda $\mathrm{V}$ nodules, and limited sensitivity of the 7-panel testing, surgery is recommended in all Bethesda $\mathrm{V}$ patients. If performed, genetic testing may modulate the extent of thyroid and lymph-node surgery. The similar performances of the 7-panel testing in Bethesda III and IV nodules suggest using it in both categories of patients. Surgery appears to be recommended when a molecular alteration is detected, particularly $B R A F$ or $P A X 8 / P P A R \gamma$ which are highly specific for cancer. In the absence of molecular alteration, a US and FNAB control at 6-12 months could be performed, except for nodules suspicious of cancer for other reasons, e.g., history of radiation, serum calcitonin increase or EU-Tirads 5, which should be operated on. The absence of volume progression at 1 year, all the more if associated with a benign cytology, would allow continuing spaced monitoring.

An issue that has not been resolved to date is whether 7panel molecular testing of cytology specimens could help predict long-term outcomes in the cancer patient subgroup. Our data show that the outcome of patients with or without molecular alterations was not different, suggesting that mutational testing in FNAB with 7-gene panel may play a minimal role in identifying high-risk cancers. Again, since the BRAF mutation is the most common alteration associated with aggressive behaviour in PTC [3], the fairly low rates of PTC and $B R A F$-mutated PTC in our series may have contributed to such negative results. Above all, there is evidence pointing out that the presence of multiple molecular alterations or mutations such as those of TERT [33], TP53 or PIK3CA [34, 35], that are not included in the 7- gene panel, have a higher prognostic value. In any event, this prognostic analysis has been performed in a limited number of patients and must be confirmed in larger series.

The strengths of the present study are its prospective design, the confirmation of IC by an independent review, the histological gold standard and the ability to assess the prognostic value of the mutational testing with a significant follow-up. The study also presents some limitations. One is that certain mutations of the RAS genes, notably HRAS codon 13 mutations previously reported in anaplastic thyroid cancer, and KRAS codon 61 in both PTC and PDTC, were not analyzed. This may have underestimated the number of positive cases although these mutations are uncommon [35]. Above all, a limitation was not having access to NGS multi-gene panel such as ThyroSeq v3 [36] or other recently reported technologies [37-39]. The use of multi-gene NGS panels makes it possible to analyse more than one hundred genes and to detect different classes of genetic alterations, including mutations, insertions and deletions, gene fusions, gene expression alterations and copy number variations to improve diagnostic accuracy and potentially prognostic value of genetic testing on cytologically indeterminate nodules. When the study was launched, the NGS multi-gene panel was not available. The cost of NGS panels remains a critical problem, raised in the same way by the genomic tests currently available. In countries or institutions subject to financial constraints, and before the widespread use of NGS technics, this would support a relevant role in clinical practice for a small panel of genes.

In conclusion, this prospective study confirms that the 7panel mutation testing is a simple and low-cost tool to help the clinician manage patients with cytologically indeterminate nodules. In the subgroup of cancer patients, however, mutational testing has not been shown to have a significant prognostic value. 
Acknowledgements We are indebted to all clinical research associates working in each centre, especially Chantal Rieux, Theary Cheav and Paul Ihout. We are also grateful to Helen Lapasset for her assistance in reviewing the manuscript.

Funding The study was supported by grants from the "Fondation de l'Avenir" and the French Society of Endocrinology.

\section{Compliance with ethical standards}

Ethical approval This study was approved by the Local Ethics Committee and the French Health Authorities, and was conducted according to the provisions of the Declaration of Helsinki and the Good Clinical Practice Guidelines of the International Conference of Harmonization. Written informed consent was obtained from all patients.

Conflict of interest The authors declare that they have no conflict of interest.

Publisher's note Springer Nature remains neutral with regard to jurisdictional claims in published maps and institutional affiliations.

Open Access This article is licensed under a Creative Commons Attribution 4.0 International License, which permits use, sharing, adaptation, distribution and reproduction in any medium or format, as long as you give appropriate credit to the original author(s) and the source, provide a link to the Creative Commons license, and indicate if changes were made. The images or other third party material in this article are included in the article's Creative Commons license, unless indicated otherwise in a credit line to the material. If material is not included in the article's Creative Commons license and your intended use is not permitted by statutory regulation or exceeds the permitted use, you will need to obtain permission directly from the copyright holder. To view a copy of this license, visit http://creativecommons. org/licenses/by/4.0/.

\section{References}

1. Z.W. Baloch, V.A. Livolsi, S.L. Asa, J. Rosai, M.J. Merino, G. Randolph, P. Vielh, R.M. DeMay, M.K. Sidawy, W.J. Frable, Diagnostic terminology and morphologic criteria for cytologic diagnosis of thyroid lesions: a synopsis of the National Cancer Institute Thyroid Fine-Needle Aspiration State of the Science Conference. Diagn. Cytopathol. 36, 425-437 (2008)

2. B.R. Haugen, E.K. Alexander, K.C. Bible, G.M. Doherty, S.J. Mandel, Y.E. Nikiforov, F. Pacini, G.W. Randolph, A.M. Sawka, M. Schlumberger, K.G. Schuff, S.I. Sherman, J.A. Sosa, D.L. Steward, R.M. Tuttle, L. Wartofsky, 2015 American Thyroid Association Management Guidelines for Adult Patients with Thyroid Nodules and Differentiated Thyroid Cancer: The American Thyroid Association Guidelines Task Force on Thyroid Nodules and Differentiated Thyroid Cancer. Thyroid 26, 1-133 (2016)

3. M. Xing, A.S. Alzahrani, K.A. Carson, D. Viola, R. Elisei, B. Bendlova, L. Yip, C. Mian, F. Vianello, R.M. Tuttle, E. Robenshtok, J.A. Fagin, E. Puxeddu, L. Fugazzola, A. Czarniecka, B. Jarzab, C.J. O'Neill, M.S. Sywak, A.K. Lam, G. Riesco-Eizaguirre, P. Santisteban, H. Nakayama, R.P. Tufano, S.I. Pai, M.A. Zeiger, W.H. Westra, D.P. Clark, R. Clifton-Bligh, D. Sidransky, P.W. Ladenson, V. Sykorova, Association between BRAF V600E mutation and mortality in patients with papillary thyroid cancer. JAMA 309, 1493-1501 (2013)
4. R. Paschke, S. Cantara, A. Crescenzi, B. Jarzab, T.J. Musholt, S. M. Sobrinho, European thyroid association guidelines regarding thyroid nodule molecular fine-needle aspiration cytology diagnostics. Eur. Thyroid J. 6, 115-129 (2017)

5. S.K. Kim, T.S. Hwang, Y.B. Yoo, H.S. Han, D.L. Kim, K.H. Song, S.D. Lim, W.S. Kim, N.S. Paik, Surgical results of thyroid nodules according to a management guideline based on the BRAFV600E mutation status. J. Clin. Endocrinol. Metab. 96, 658-664 (2011)

6. Y.E. Nikiforov, N.P. Ohori, S.P. Hodak, S.E. Carty, S.O. Lebeau, R.L. Ferris, L. Yip, R.R. Seethala, M.E. Tublin, M.T. Stang, C. Coyne, J.T. Johnson, A.F. Stewart, M.N. Nikiforova, Impact of mutational testing on the diagnosis and management of patients with cytologically indeterminate thyroid nodules: a prospective analysis of 1056 FNA samples. J. Clin. Endocrinol. Metab. 96, 3390-3397 (2011)

7. Y.E. Nikiforov, S.E. Carty, S.I. Chiosea, C. Coyne, U. Duvvuri, R.L. Ferris, W.E. Gooding, S.O. Lebeau, N.P. Ohori, R.R. Seethala, M.E. Tublin, L. Yip, M.N. Nikiforova, Impact of the multigene thyroseq next-generation sequencing assay on cancer diagnosis in thyroid nodules with atypia of undetermined significance/ follicular lesion of undetermined significance cytology. Thyroid 25, 1217-1223 (2015)

8. D.L. Steward, S.E. Carty, R.S. Sippel, S.P. Yang, J.A. Sosa, J.A. Sipos, J.J. Figge, S. Mandel, B.R. Haugen, K.D. Burman, Z.W. Baloch, R.V. Lloyd, R.R. Seethala, W.E. Gooding, S.I. Chiosea, C. Gomes-Lima, R.L. Ferris, J.M. Folek, R.A. Khawaja, P. Kundra, K.S. Loh, C.B. Marshall, S. Mayson, K.L. McCoy, M.E. Nga, K.Y. Ngiam, M.N. Nikiforova, J.L. Poehls, M.D. Ringel, H. Yang, L. Yip, Y.E. Nikiforov, Performance of a multigene genomic classifier in thyroid nodules with indeterminate cytology: a prospective blinded multicenter study. JAMA Oncol. 5, 204-212 (2019)

9. K.N. Patel, T.E. Angell, J. Babiarz, N.M. Barth, T. Blevins, Q.Y. Duh, R.A. Ghossein, R.M. Harrell, J. Huang, G.C. Kennedy, S.Y. Kim, R.T. Kloos, V.A. Livolsi, G.W. Randolph, P.M. Sadow, M. H. Shanik, J.A. Sosa, S.T. Traweek, P.S. Walsh, D. Whitney, M. W. Yeh, P.W. Ladenson, Performance of a genomic sequencing classifier for the preoperative diagnosis of cytologically indeterminate thyroid nodules. JAMA Surg. 153, 817-824 (2018)

10. M. Endo, F. Nabhan, K. Porter, K. Roll, L.A. Shirley, I. Azaryan, D. Tonkovich, J. Perlick, L.E. Ryan, R. Khawaja, S. Meng, J.E. Phay, M.D. Ringel, J.A. Sipos, Afirma gene sequencing classifier compared with gene expression classifier in indeterminate thyroid nodules. Thyroid 29, 1115-1124 (2019)

11. S. Bardet, R. Ciappuccini, C. Pellot-Barakat, H. Monpeyssen, J.J. Michels, F. Tissier, D. Blanchard, F. Menegaux, R.D. de, M. Lefort, Y. Reznik, A. Rouxel, N. Heutte, F. Brenac, A. Leconte, C. Buffet, B. Clarisse, L. Leenhardt, Shear wave elastography in thyroid nodules with indeterminate cytology: results of a prospective bicentric study. Thyroid 27, 1441-1449 (2017)

12. Pathology and genetics of tumours of endocrin organs. Word Health Organization Classification of Tumours. Lyon 2004: IARC Press (2011)

13. G. Russ, S.J. Bonnema, M.F. Erdogan, C. Durante, R. Ngu, L. Leenhardt, European thyroid association guidelines for ultrasound malignancy risk stratification of thyroid nodules in adults: the EUTIRADS. Eur. Thyroid J. 6, 225-237 (2017)

14. E. Labourier, A. Shifrin, A.E. Busseniers, M.A. Lupo, M.L. Manganelli, B. Andruss, D. Wylie, S. Beaudenon-Huibregtse, Molecular testing for miRNA, mRNA, and DNA on fine-needle aspiration improves the preoperative diagnosis of thyroid nodules with indeterminate cytology. J. Clin. Endocrinol. Metab. 100, 2743-2750 (2015)

15. M. Eszlinger, S. Piana, A. Moll, E. Bosenberg, A. Bisagni, A. Ciarrocchi, M. Ragazzi, R. Paschke, Molecular testing of thyroid 
fine-needle aspirations improves presurgical diagnosis and supports the histologic identification of minimally invasive follicular thyroid carcinomas. Thyroid 25, 401-409 (2015)

16. M. Eszlinger, A. Krogdahl, S. Munz, C. Rehfeld, E.M. Precht Jensen, C. Ferraz, E. Bosenberg, N. Drieschner, M. Scholz, L. Hegedus, R. Paschke, Impact of molecular screening for point mutations and rearrangements in routine air-dried fine-needle aspiration samples of thyroid nodules. Thyroid 24, 305-313 (2014)

17. S. Beaudenon-Huibregtse, E.K. Alexander, R.B. Guttler, J.M. Hershman, V. Babu, T.C. Blevins, P. Moore, B. Andruss, E. Labourier, Centralized molecular testing for oncogenic gene mutations complements the local cytopathologic diagnosis of thyroid nodules. Thyroid 24, 1479-1487 (2014)

18. S. Cantara, M. Capezzone, S. Marchisotta, S. Capuano, G. Busonero, P. Toti, A. Di Santo, G. Caruso, A.F. Carli, L. Brilli, A. Montanaro, F. Pacini, Impact of proto-oncogene mutation detection in cytological specimens from thyroid nodules improves the diagnostic accuracy of cytology. J. Clin. Endocrinol. Metab. 95, 1365-1369 (2010)

19. Y.E. Nikiforov, D.L. Steward, T.M. Robinson-Smith, B.R. Haugen, J.P. Klopper, Z. Zhu, J.A. Fagin, M. Falciglia, K. Weber, M. N. Nikiforova, Molecular testing for mutations in improving the fine-needle aspiration diagnosis of thyroid nodules. J. Clin. Endocrinol. Metab. 94, 2092-2098 (2009)

20. M. Bongiovanni, F. Molinari, M. Eszlinger, R. Paschke, J. Barizzi, E. Merlo, L. Giovanella, F. Fasolini, F. Cattaneo, F. Ramelli, L. Mazzucchelli, M. Frattini, Laser capture microdissection is a valuable tool in the preoperative molecular screening of follicular lesions of the thyroid: an institutional experience. Cytopathology 26, 288-296 (2015)

21. I. Mancini, P. Pinzani, C. Pupilli, L. Petrone, M.L. De Feo, L. Bencini, M. Pazzagli, G. Forti, C. Orlando, A high-resolution melting protocol for rapid and accurate differential diagnosis of thyroid nodules. J. Mol. Diagn. 14, 501-509 (2012)

22. C. Bellevicine, R. Sgariglia, I. Migliatico, E. Vigliar, M. D’Anna, M.A. Nacchio, N. Serra, U. Malapelle, M. Bongiovanni, G. Troncone, Different qualifiers of AUS/FLUS thyroid FNA have distinct BRAF, RAS, RET/PTC, and PAX8/PPARg alterations. Cancer Cytopathol. 126, 317-325 (2018)

23. C. Li, K.C. Lee, E.B. Schneider, M.A. Zeiger, BRAF V600E mutation and its association with clinicopathological features of papillary thyroid cancer: a meta-analysis. J. Clin. Endocrinol. Metab. 97, 4559-4570 (2012)

24. A.R. Hong, J.A. Lim, T.H. Kim, H.S. Choi, W.S. Yoo, H.S. Min, J.K. Won, K.E. Lee, K.C. Jung, D.J. Park, Y.J. Park, The frequency and clinical implications of the BRAF(V600E) mutation in papillary thyroid cancer patients in korea over the past two decades. Endocrinol. Metab. 29, 505-513 (2014)

25. S. Vargas-Salas, J.R. Martinez, S. Urra, J.M. Dominguez, N. Mena, T. Uslar, M. Lagos, M. Henriquez, H.E. Gonzalez, Genetic testing for indeterminate thyroid cytology: review and metaanalysis. Endocr. Relat. Cancer 25, R163-R177 (2018)

26. V. Maximo, J. Lima, H. Prazeres, P. Soares, M. Sobrinho-Simoes, The biology and the genetics of Hurthle cell tumors of the thyroid. Endocr. Relat. Cancer 19, R131-R147 (2012)

27. M.M. de Vries, R. Celestino, P. Castro, C. Eloy, V. Maximo, J.E. van der Wal, J.T. Plukker, T.P. Links, R.M. Hofstra, M. SobrinhoSimoes, P. Soares, RET/PTC rearrangement is prevalent in follicular Hurthle cell carcinomas. Histopathology 61, 833-843 (2012)

28. R.K. Gopal, K. Kubler, S.E. Calvo, P. Polak, D. Livitz, D. Rosebrock, P.M. Sadow, B. Campbell, S.E. Donovan, S. Amin, B. J. Gigliotti, Z. Grabarek, J.M. Hess, C. Stewart, L.Z. Braunstein,
P.F. Arndt, S. Mordecai, A.R. Shih, F. Chaves, T. Zhan, C.C. Lubitz, J. Kim, A.J. Iafrate, L. Wirth, S. Parangi, I. Leshchiner, G. H. Daniels, V.K. Mootha, D. Dias-Santagata, G. Getz, D.G. McFadden, Widespread chromosomal losses and mitochondrial DNA alterations as genetic drivers in hurthle cell carcinoma. Cancer Cell 34, 242-255 (2018)

29. I. Ganly, V. Makarov, S. Deraje, Y. Dong, E. Reznik, V. Seshan, G. Nanjangud, S. Eng, P. Bose, F. Kuo, L.G.T. Morris, I. Landa, P.B. Carrillo Albornoz, N. Riaz, Y.E. Nikiforov, K. Patel, C. Umbricht, M. Zeiger, E. Kebebew, E. Sherman, R. Ghossein, J.A. Fagin, T.A. Chan, Integrated genomic analysis of hurthle cell cancer reveals oncogenic drivers, recurrent mitochondrial mutations, and unique chromosomal landscapes. Cancer Cell 34, 256-270 (2018)

30. A. Najafian, S. Noureldine, F. Azar, C. Atallah, G. Trinh, E.B. Schneider, R.P. Tufano, M.A. Zeiger, RAS mutations, and RET/ PTC and PAX8/PPAR-gamma chromosomal rearrangements are also prevalent in benign thyroid lesions: implications thereof and a systematic review. Thyroid 27, 39-48 (2017)

31. Z. Zhu, R. Ciampi, M.N. Nikiforova, M. Gandhi, Y.E. Nikiforov, Prevalence of RET/PTC rearrangements in thyroid papillary carcinomas: effects of the detection methods and genetic heterogeneity. J. Clin. Endocrinol. Metab. 91, 3603-3610 (2006)

32. M. Kim, M.J. Jeon, H.S. Oh, S. Park, T.Y. Kim, Y.K. Shong, W. B. Kim, K. Kim, W.G. Kim, D.E. Song, BRAF and RAS mutational status in noninvasive follicular thyroid neoplasm with papillary-like nuclear features and invasive subtype of encapsulated follicular variant of papillary thyroid carcinoma in Korea. Thyroid 28, 504-510 (2018)

33. M. Melo, A.G. da Rocha, J. Vinagre, R. Batista, J. Peixoto, C. Tavares, R. Celestino, A. Almeida, C. Salgado, C. Eloy, P. Castro, H. Prazeres, J. Lima, T. Amaro, C. Lobo, M.J. Martins, M. Moura, B. Cavaco, V. Leite, J.M. Cameselle-Teijeiro, F. Carrilho, M. Carvalheiro, V. Maximo, M. Sobrinho-Simoes, P. Soares, TERT promoter mutations are a major indicator of poor outcome in differentiated thyroid carcinomas. J. Clin. Endocrinol. Metab. 99, E754-E765 (2014)

34. M.R. Haroon Al Rasheed, B. Xu, Molecular alterations in thyroid carcinoma. Surg. Pathol. Clin. 12, 921-930 (2019)

35. N. Pozdeyev, L.M. Gay, E.S. Sokol, R. Hartmaier, K.E. Deaver, S. Davis, J.D. French, P.V. Borre, D.V. LaBarbera, A.C. Tan, R. E. Schweppe, L. Fishbein, J.S. Ross, B.R. Haugen, D.W. Bowles, Genetic analysis of 779 advanced differentiated and anaplastic thyroid cancers. Clin. Cancer Res. 24, 3059-3068 (2018)

36. M.N. Nikiforova, S. Mercurio, A.I. Wald, M.M. Barbi de, K. Callenberg, L. Santana-Santos, W.E. Gooding, L. Yip, R.L. Ferris, Y.E. Nikiforov, Analytical performance of the ThyroSeq v3 genomic classifier for cancer diagnosis in thyroid nodules. Cancer 124, 1682-1690 (2018)

37. M. Sponziello, C. Brunelli, A. Verrienti, G. Grani, V. Pecce, L. Abballe, V. Ramundo, G. Damante, D. Russo, C. P. Lombardi, C. Durante, E. D. Rossi, P. Straccia, G. Fadda, S. Filetti, Performance of a dual-component molecular assay in cytologically indeterminate thyroid nodules. Endocrine 68, 458-465 (2020)

38. K.K. Ablordeppey, V.A. Timmaraju, J.W. Song-Yang, S. Yaqoob, C. Narick, A. Mireskandari, S.D. Finkelstein, G. Kumar, Development and analytical validation of an expanded mutation detection panel for next-generation sequencing of thyroid nodule aspirates. J. Mol. Diagn. 22, 355-367 (2020)

39. D. De Biase, G. Acquaviva, M. Visani, V. Sanza, C.M. Argento, L.A. De, T. Maloberti, A. Pession, G. Tallini, Molecular diagnostic of solid tumor using a next generation sequencing customdesigned multi-gene panel. Diagnostics 10, 250 (2020) 